\title{
Warfarin dosing strategies evolution and its progress in the era of precision medicine, a narrative review
}

\author{
Amr Mohamed Fahmi ${ }^{1}$ (D) Hazem Elewa ${ }^{2,3} \mathbb{B} \cdot$ Islam El Jilany ${ }^{4}$
}

Received: 14 November 2021 / Accepted: 9 February 2022 / Published online: 5 March 2022

(c) The Author(s) 2022

\begin{abstract}
Background For decades, vitamin $\mathrm{K}$ antagonists and specifically warfarin, have been the sole agents used orally to manage thromboembolic conditions, including stroke and venous thromboembolism (VTE). Several factors lead to warfarin dose variability, including genetic and non-genetic factors which made warfarin management challenging especially at the initiation phase. To overcome the challenges with warfarin dosing at initiation, strategies other than conventional or fixed dosing were introduced and explored. Aim In this narrative review, we aim to discuss and critique the different dosing strategies for warfarin at initiation with more focus on genotype-guided warfarin dosing and the most recent supporting evidence for and against its use. Method Medline database was searched from 1965 to July 2021. Articles addressing different warfarin dosing methods were screened for inclusion. Results A number of methods exist for warfarin initiation. Studies comparing different dosing methods for initiation yielded conflicting outcomes due to differences in study design, population studied, comparator, and outcomes measured. Conclusions Looking at the big picture, the use of genetic dosing for warfarin initiation can lead to better outcomes. Whether these better outcomes are clinically or economically beneficial remains controversial.
\end{abstract}

Keywords CYP2C9 - Genetic-guided warfarin dosing · Warfarin clinical dosing · Warfarin dosing algorithms · Warfarin fixed dosing $\cdot$ VKORC1—CYP4F2

\section{Impacts on practice}

- Warfarin remains the drug of choice for the prevention of thrombosis in a number of indications and therefore a focus on the best dosing methods is still needed.

- Genetic-guided warfarin dosing is the most precise method, but not the most widespread.

- We describe most common warfarin dosing methods which could help prescribers of vitamin k antagonists.

Hazem Elewa

elewahazem@gmail.com

1 Clinical pharmacist, Hamad Medical Corporation, Doha, Qatar

2 College of Pharmacy, QU Health, Qatar University, P.O. Box 2713, Doha, Qatar

3 Biomedical and Pharmaceutical Research Unit, QU Health, Qatar University, Doha, Qatar

4 School of Pharmacy, University of Florida, Gainesville, USA
- We summarize the most common warfarin genetic variants and dosing algorithms and how they compare to empirical warfarin dosing.

\section{Introduction}

For decades, vitamin $\mathrm{K}$ antagonists and specifically warfarin, have been the sole agents used orally to manage thromboembolic conditions, including stroke, deep vein thrombosis (DVT) and pulmonary embolism (PE). With the discovery of direct oral anticoagulants (DOACs), more healthcare providers prefer them over warfarin due to their ease of use, fast onset and offset, and the lack of need for monitoring. In the last decade in the United States, warfarin prescribing dropped from 77 to $12 \%$ in specific indications like atrial fibrillation (AF) [1]. Despite the increased use of DOACs, warfarin remains the main drug of choice for stroke prevention in patients with mechanical heart valve replacement, AF with significant mitral valve stenosis or hypertrophic cardiomyopathy, and antiphospholipid antibody syndrome $[2,3]$. Warfarin is also preferred in obese patients (body 
mass index $>40 \mathrm{Kg} / \mathrm{m}^{2}$ ), those with poor renal function (creatinine clearance $<15 \mathrm{ml} / \mathrm{min}$ ) and breastfeeding women [4].

Warfarin mediates its anticoagulant effect by inhibiting the vitamin $\mathrm{K}$ epoxide reductase enzyme (VKOR). The inhibition of VKOR leads to a decrease in the reduced (active) form of vitamin K, which inhibits the activation of the coagulation factors II, VII, IX, and X and produces the anticoagulant effect of warfarin [4]. Several factors lead to warfarin dose variability, including genetic and non-genetic factors [4]. Almost half of this interpatient variability has been attributed to clinical and genetic factors, while the remaining variability remains unexplained [5]. And since warfarin has a narrow therapeutic window, dosing variability has made warfarin management challenging especially at the initiation phase. It also makes the frequent measurement of international normalized ratio (INR) necessary to ensure optimal anticoagulation. To overcome the challenges with warfarin dosing at initiation, strategies other than conventional or fixed dosing were introduced and explored [6].

\section{Aim}

In this narrative review, we discuss and critique the different dosing strategies for warfarin at initiation with more focus on genotype-guided warfarin dosing and the most recent supporting evidence for and against its use.

\section{Method}

Medline database was searched from 1965 to July 2021 for keywords such as: warfarin, pharmacogenomics, pharmacogenetics, warfarin pharmacogenomics, warfarin dosing and warfarin algorithms. Search was limited to English language, humans, and adults (18 years and older). Related articles were also screened to capture any articles not reported in the results. The first and second investigators screened the resulting articles for inclusion. Articles were included if the authors addressed:

1. Warfarin clinical dosing: reported the significance of different clinical variables affecting warfarin dosing e.g.: Age, body surface area (BSA), sex, diet and medications.

2. Warfarin fixed dosing: compared different warfarin loading doses or warfarin nomograms at initiation.

3. Genetic-guided warfarin dosing: compared different warfarin pharmacogenetic dosing algorithms to each other or derived their own algorithm. Also, if pharmacogenetic-guided dosing was compared to clinical or fixed dosing.

\section{Results}

\section{Fixed dosing}

Fixed dosing is one of the most widely used methods for warfarin dosing. It involves administering a predetermined warfarin dose for two consecutive days and measuring the INR on the third or fourth day. Then, clinicians revisit a warfarin nomogram, which contains warfarin doses according to patient's INR, and recommends dose modification according to the observed INR. Clinicians may prefer to give a loading dose, which is defined as "an initial warfarin dose" for 1-2 days [7]. A typical loading dose ranges from 5 to $10 \mathrm{mg}$ [8].

In the last three decades, a number of trials were published looking at how the use of usual warfarin doses " $\leq 5 \mathrm{mg}$ " compare to the use of high warfarin doses "> $5 \mathrm{mg}$ ". These trials had differences in their designs, outcomes and yielded conflicting results. In a small prospective study, Crowther et al. compared an initial dose of $5 \mathrm{mg}$ versus $10 \mathrm{mg}$. Most of the patients had acute thromboembolism. There were no differences between the two groups in achieving a therapeutic INR on two consecutive days, i.e., days 3 and 4 or days 4 and 5 of treatment [9]. It should be noted that most of the patients in this study were hospitalized, which may have made them more sensitive to warfarin therapy when compared to those in the outpatient setting. This sensitivity can be attributed to other co-morbid diseases and poor dietary intake [10]. Kovacs et al. tested the $5 \mathrm{mg}$ nomogram used by Crowther et al. in comparison to his $10 \mathrm{mg}$ nomogram in outpatients suffering from VTE [10]. Patients in the $10 \mathrm{mg}$ group achieved therapeutic INR 1.4 days earlier than the $5 \mathrm{mg}$ nomogram without increasing the risk of bleeding. Additionally, patients in the $10 \mathrm{mg}$ group were more likely to achieve a therapeutic INR by day $5(83 \%$ vs. $46 \% ; P$-value $(P)<0.001)$. Although this study was one of the main studies advocating for a loading dose of $10 \mathrm{mg}$, it is important to note that the authors excluded patients with high bleeding risk. A third openlabel randomized study by Quiroz et al. comparing two warfarin initiation nomograms ( $5 \mathrm{mg}$ vs. $10 \mathrm{mg}$ ) found no difference in the time needed to achieve therapeutic INR for two consecutive days (median time $=5$ days, log-rank test $P=0.69$ ) [11]. Another retrospective cohort study included outpatients who were treated for VTE and were started on the $10 \mathrm{mg}$ nomogram [12]. The aim was to increase the generalizability of the previously published $10 \mathrm{mg}$ nomogram. Compared to patients who were nonadherent to the nomogram, those who were adherent were more likely to have a therapeutic INR by day 5 , whereas no difference existed in bleeding and thrombosis recurrence. A systematic review and meta-analysis published in 2013 
and updated in 2016 included all randomized trials comparing loading dose of $5 \mathrm{mg}$ versus $10 \mathrm{mg}$. The authors concluded that there were no differences between the $5 \mathrm{mg}$ and $10 \mathrm{mg}$ groups in the outcome of INR in range by day 5 [Relative risk $(\mathrm{RR})=1.17,95 \% \mathrm{CI} 0.77-1.77, P=0.46$ ], although the heterogeneity was high $\left(\mathrm{I}^{2}=83 \%\right)[13,14]$. During sensitivity analyses, removal of the study with the highest contribution to heterogeneity confirmed a lack of difference between the two groups (RR, 0.98; 95\% CI, $0.73-1.32, P=0.9, \mathrm{I}^{2}=44 \%$ ).

The 2012 American College of Chest Physicians (ACCP) guidelines for oral anticoagulants recommend starting patients on a $10 \mathrm{mg}$ warfarin loading, especially in healthy ambulatory individuals [8]. The guidelines were published before the previously mentioned meta-analysis, which may explain the discrepancies between the recommendation and the evidence from the meta-analysis. The previous 2008 ACCP guidelines and the British Society for standards of Hematology (BCSH) 2011 provide options to give patients a loading dose of 5-10 mg [15, 16].

In summary, the evidence is inconclusive to recommend $10 \mathrm{mg}$ over $5 \mathrm{mg}$ as a loading dose. Based on the literature, patients who were more likely to benefit from the $10 \mathrm{mg}$ regimen were outpatients, younger, had higher vitamin $\mathrm{K}$ intake, less co-morbid diseases, and fewer drug interactions.

\section{Clinical dosing}

Multiple factors can affect warfarin dosing, including genetic and non-genetic (clinical) factors, both of which explain more than half of the variability in warfarin dose requirements [17]. Apart from genetics, non-genetic factors were explored in several studies [17-19]. Some of the wellestablished clinical factors affecting warfarin are age, sex, body mass index, race, baseline INR, indication/target INR, liver disease, and drug-drug interactions.

Age is one of the earliest identified factors affecting warfarin dose [20]. Redwood et al. examined the effect of age on warfarin dose and concluded that, on average, patients greater than 70 years of age require $25-30 \%$ lower warfarin doses than those less than 30 years of age [21]. Similarly, a stud by Gurwitz et al. assessed the effect of aging on oral anticoagulant dose requirements [22]. Patients who were in the highest age group were more likely to require a lower warfarin dose. Also, those between 50 and 70 years of age had a $10 \%$ reduction in their mean warfarin dose as compared to the younger group ( $7.2 \mathrm{mg}$ vs. $8.1 \mathrm{mg} ; P=0.0002)$. In the sub-group of patients above 70 years of age, there was a higher incidence of bleeding when compared to those younger than 50 years of age (RR, 1.8; 95\% CI, 1.12-3; $P=0.016$ ) [23]. Gage et al. quantified the impact of age on warfarin dose, and he observed that every decade increase in age was associated with a $7-13 \%$ decrease in warfarin maintenance dose [18].

Weight and its surrogates BSA and body mass index (BMI) is another widely studied factor associated with warfarin dose variability. According to the Gage algorithm, with every $0.26 \mathrm{~m}^{2}$ increase in BSA, warfarin dose increased by $15 \%$ [18]. Another study showed that an increase in BMI by 1 point is associated with a $0.69 \mathrm{mg}$ increase in weekly warfarin dose requirements [24]. Others have shown that BMI $>40 \mathrm{~kg} / \mathrm{m}^{2}$ (morbidly obese) was significantly associated with higher warfarin dose requirements when compared with obese, overweight, normal weight, and underweight individuals [25].

Race has been an important source of variability for many drugs, including warfarin. This effect was highlighted in a study by Absher and colleagues, which included 146 patients from a community hospital and an outpatient anticoagulation clinic. African American race was one of 5 factors associated with a warfarin dose higher than $5 \mathrm{mg}$. Also, African American patients required extra $1.3 \mathrm{mg}$ daily warfarin dose when compared to their white counterparts [26]. Another retrospective cohort of 345 patients found that African American patients had the highest average weekly warfarin doses [43 mg (39-47)], followed by Whites [36 mg (34-39) ], Hispanics [31 mg (25-37)], while the lowest average weekly warfarin doses were for those with Asian ancestry [24 mg (21-27)] [27].

Numerous drugs interact with warfarin, a good number of which can affect warfarin maintenance dose, especially when the interacting medication is started or stopped. Warfarin is a racemic mixture of $\mathrm{S}$-warfarin and $\mathrm{R}$-warfarin where the $\mathrm{S}$-isomer is more potent than the $\mathrm{R}$ [8]. S-warfarin is primarily metabolized by Cytochrome P 4502 C9 (CYP2C9), while R-warfarin is metabolized by Cytochrome P 4503 A4 (CYP3A4). Warfarin drug interactions are either pharmacokinetic or pharmacodynamic interactions [8]. The pharmacokinetic interactions are mainly due to induction or inhibition of CYP2C9, which is the main enzyme responsible for the metabolism of warfarin (and/or CYP3A4 at a lesser extent) [8]. Patients on a stable maintenance dose of warfarin who are started on a potent drug interacting medication usually require a change in warfarin dose [8]. Most commonly, amiodarone, azole antifungals, phenytoin, rifampicin, trimethoprim/sulfamethoxazole, and the use of statins are included in warfarin maintenance dose algorithms. However, quantification of the effect of the interacting drug on warfarin dose is complicated and varies based on the interacting medication, genetic variants affecting the responsible metabolizing enzyme and other inter-individual variations [28]. For example, 30-50\% warfarin dose reduction is recommended with amiodarone initiation, whereas a $25-33 \%$ reduction is recommended for fenofibrate [29]. 
Most of the demographic and clinical elements discussed above were incorporated in algorithms along with genetic factors and then introduced as genetic algorithms. However, these algorithms allow healthcare providers to use the clinical factors alone, especially when genetic factors are unknown or pending, to predict a warfarin maintenance dose, although with less accuracy. Those algorithms will be discussed in the genetic algorithms section.

Genotype-guided warfarin dosing

\section{Genotype-guided warfarin dosing}

Warfarin dosing is affected by a number of genetic variants that could unease the process of initiation and discontinuation. The main three genes that carry these variants are CYP2C9, VKORC1, and CYP4F2 (Table 1). CYP2C9 codes for CYP2C9 which plays an important role in clearing the more potent $\mathrm{S}$-warfarin enantiomer. The VKORCl on the other hand codes for VKOR enzyme, which is responsible for the activation of vitamin $\mathrm{K}$, which in turn activates the coagulation factors. Warfarin exerts its anticoagulant effect through inhibition of the VKOR enzyme. The CYP4F2 codes for CYP4F2 enzyme, which is responsible for metabolizing the activated form of vitamin $\mathrm{K}$, rendering it inactive.

Ever since the FDA proposed the pharmacogenetic dosing table to be added to warfarin labeling [30], groups and consortia such as the Pharmacogenomics Knowledge Base (PharmGKB) and the Dutch Pharmacogenetics Working Group (DPWG) started publishing guidelines on how to use the available genetic information to optimize warfarin dosing [31, 32]. Among these resources are the clinical Pharmacogenetics Implementation Consortium "CPIC" guidelines, which help clinicians understand how genetic test results can be used in prescribing decisions for certain medications [33]. Both the American Society of Health-system Pharmacist "ASHP" and the American Society of Clinical Pharmacology and Therapeutics "ASCPT" endorse the CPIC guidelines. The CPIC guidelines for CYP2C9 and VKORC1 genotypes and warfarin dosing were published in 2011 and updated in 2017 [34].

\section{Warfarin genetic algorithms}

Genetic dosing uses patients' genetic test results to predict the initial warfarin dose. There are mainly two approaches to genetic dosing; the first is the FDA pharmacogenetic table, which can be found in the warfarin package insert and was added in early 2010 (Table 2 ) [35]. With the results of patients' genetic testing for $C Y P 2 C 9$ and VKORCI (c.$1639 G>A$ ), clinicians can use this table as a guide to recommend the most appropriate warfarin dose. The table generally accounts for clinical factors (e.g., age, weight, sex, race, concomitant drugs, and comorbidities) but doesn't account for other genetic variants that may affect warfarin maintenance dose variability. The second approach is through the use of pharmacogenetic algorithms, which often include genetic components in addition to clinical factors. These pharmacogenetic algorithms are derived as linear regression equations from cohorts where every variable is tested for association with warfarin maintenance dose. Then, variables with the significant association are added to a model to be computed in the multiple linear regression analysis to yield a final equation with the highest degree of association (coefficient of determination, $\mathrm{R}^{2}$ ). The next step is the validation process which is done on a smaller similar population to compare the observed dose to the predicted dose using the algorithm. Once validated, some important measures are calculated, e.g., the mean absolute error, and the percentage of predicted warfarin doses within $20 \%$ of the actual warfarin maintenance dose. Several pharmacogenetic algorithms are available for different races. Some of these algorithms incorporate clinical factors in addition to genetic factors, which has led to a better dose prediction and refinement for warfarin maintenance doses. Of these, two algorithms are the most validated; Gage et al. and IWPC algorithms (Table 3) $[17,19]$. Other algorithms can also assist in predicting the loading dose (Avery et al.) and to refine warfarin dose after the initiation phase (Lenzini et al.) [36, 37].

The next step after derivation and validation of a pharmacogenetic-guided warfarin dosing algorithm is to compare it to the standard of care (either fixed dosing or clinical dosing) in large scale randomized controlled trials (RCTs). Three landmark studies (COAG, EUPACT and GIFT) were published in this essence [38-40]. The trials used a validated genetic guided algorithm (in addition to clinical factors) to predict warfarin maintenance dose in the genetic guided warfarin dosing arm. Most of the population recruited in the three trials were of European descent, except for the COAG trial which recruited more than $25 \%$ of patients with African descent. The EUPACT and the GIFT trials showed positive outcomes with respect to genetic guided warfarin dosing when compared to clinical or fixed warfarin dosing. On the other hand, the COAG study did not show difference in the time spent in therapeutic range. Table 4 highlights all the details of these three landmark studies, their key findings and limitations.

\section{Discussion}

Fixed dosing is still a common method to initiate warfarin dosing. Clinical dosing is as an appealing alternative strategy that considers factors proven to affect warfarin dosing when calculating the dose. There has been an indirect comparison between fixed and clinical dosing methods in the IWPC validation study [19]. Clinical dosing showed 


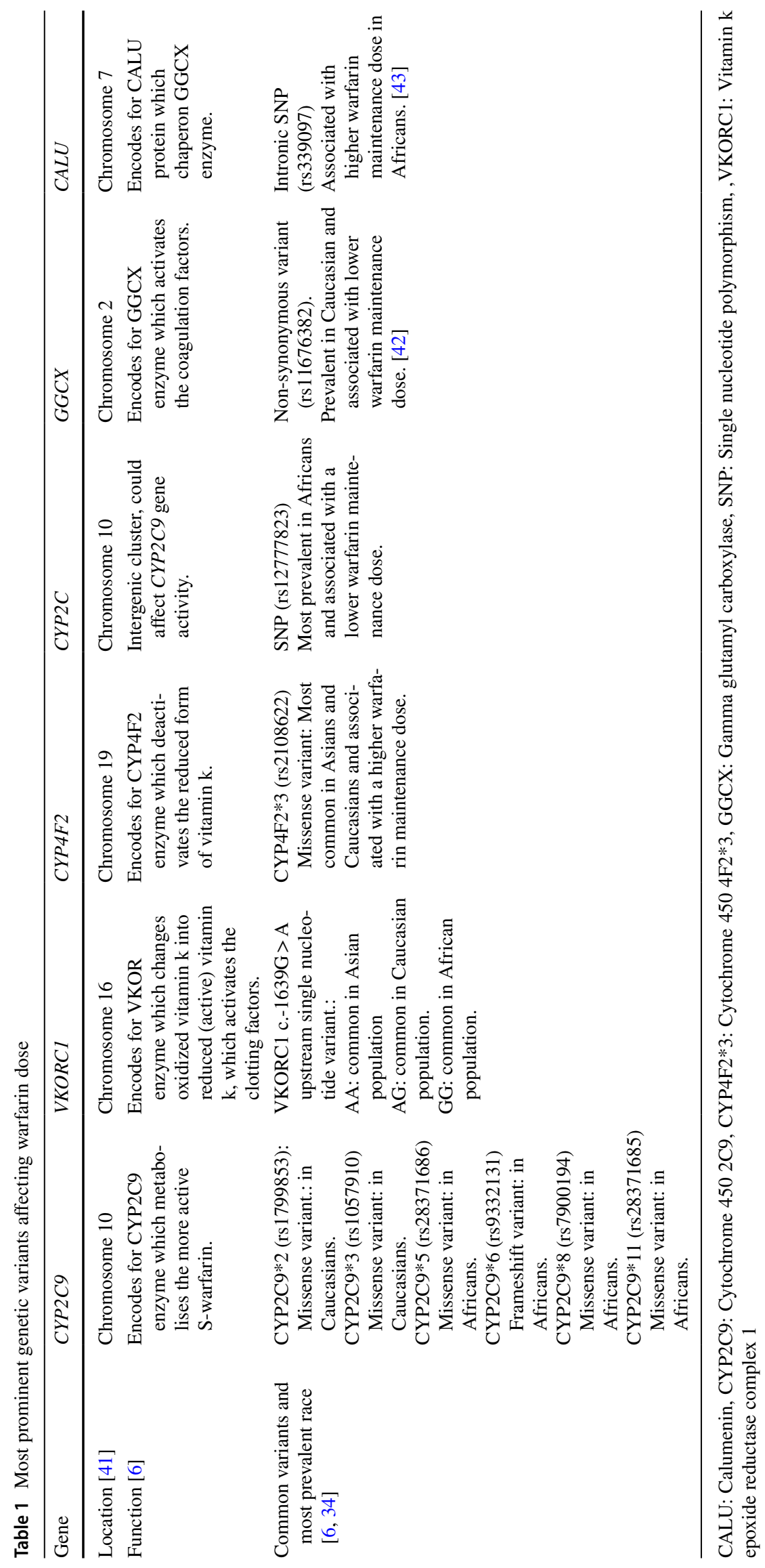


Table 2 Suggested warfarin dose based on VKORC1/ CYP2C9 genetic profile

\begin{tabular}{lllllll}
\hline VKORC $\backslash$ & $* 1 / * 1$ & $* 1 / * 2$ & $* 1 / * 3$ & $* 2 / * 2$ & $* 2 / * 3$ & $* 3 / * 3$ \\
CYP $2 C 9$ & & & & & & \\
\hline GG & $5-7 \mathrm{mg}$ & $5-7 \mathrm{mg}$ & $3-4 \mathrm{mg}$ & $3-4 \mathrm{mg}$ & $3-4 \mathrm{mg}$ & $0.5-2 \mathrm{mg}$ \\
GA & $5-7 \mathrm{mg}$ & $3-4 \mathrm{mg}$ & $3-4 \mathrm{mg}$ & $3-4 \mathrm{mg}$ & $0.5-2 \mathrm{mg}$ & $0.5-2 \mathrm{mg}$ \\
AA & $3-4 \mathrm{mg}$ & $3-4 \mathrm{mg}$ & $0.5-2 \mathrm{mg}$ & $0.5-2 \mathrm{mg}$ & $0.5-2 \mathrm{mg}$ & $0.5-2 \mathrm{mg}$ \\
\hline
\end{tabular}

(Pharmacogenetic table) Bristol-Myers Squibb. Coumadin (warfarin sodium) package insert

Table 3 Comparison of the Gage et al. and IWPC pharmacogenetic algorithms

\begin{tabular}{|c|c|c|}
\hline & Gage et al. & IWPC \\
\hline Date & Published 2008 & Published 2009 \\
\hline $\begin{array}{l}\text { Derivation } \\
\text { cohort }\end{array}$ & 1015 patients & 4043 patients \\
\hline $\begin{array}{l}\text { Validation } \\
\text { cohort }\end{array}$ & 292 patients & 1009 patients \\
\hline Age & $\begin{array}{l}\text { Derivation cohort: Mean: } 57 \text { years } \\
\text { Validation cohort: Mean: } 65 \text { years }\end{array}$ & $\begin{array}{l}\text { Validation cohort: } 53.6 \%>60 \text { years } \\
\text { Derivation cohort: } 52.3 \%>60 \text { years }\end{array}$ \\
\hline Genetic factors & $\begin{array}{l}C Y P 2 C 9 * 2 \\
C Y P 2 C 9 * 3 \\
V K O R C 1 \text { c. }-1639 G>A\end{array}$ & $\begin{array}{l}C Y P 2 C 9 * 2 \\
C Y P 2 C 9 * 3 \\
\text { VKORC1 c. }-1639 G>A\end{array}$ \\
\hline Clinical factors & $\begin{array}{l}\text { BSA, Age, Race, Sex, Amiodarone usage, Smoking } \\
\text { status, Target INR and prior DVT/PE }\end{array}$ & $\begin{array}{l}\text { Age, Height, Weight, Race, Enzyme inducer status and Amiodarone } \\
\text { status }\end{array}$ \\
\hline $\mathrm{R}^{2}$ & $54 \%$ & $43 \%$ \\
\hline MAE & $7 \mathrm{mg} / \mathrm{wk}$ & $8.5 \mathrm{mg} / \mathrm{wk}$ \\
\hline $\begin{array}{c}\text { Regression } \\
\text { equation }\end{array}$ & $\begin{array}{l}\exp [0.9751-(0.3238 \times V K O R C 1639 G>A)+(0.4317 \times B S A) \\
-(0.4008 \times C Y P 2 C 9 * 3)-(0.00745 \times \text { Age })-(0.2066 \times C Y P 2 C 9 * 2) \\
+(0.2029 \times T \text { arg et INR })-(0.2538 \times \text { Amiodarone }) \\
+(0.0922 \times \text { Smokes })-(0.0901 \times \text { African }- \text { American race }) \\
+(0.0664 \times \text { DVT } / P E \text { as Indication for Therapy })=e \text { estimated daily dose }]\end{array}$ & 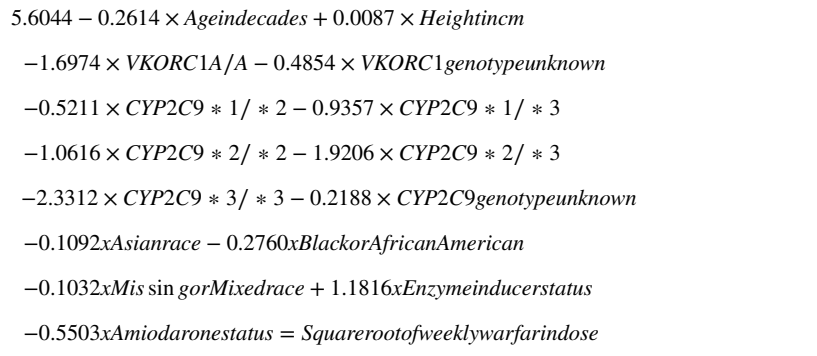 \\
\hline $\begin{array}{l}\text { Additional } \\
\text { information }\end{array}$ & $\begin{array}{l}\text { Favoured if smoking status and VTE are known. } \\
\text { Easily available at www.warfarindosing.org }\end{array}$ & $\begin{array}{l}\text { Favoured for patients receiving enzyme inducers } \\
\text { Could be accessed as an excel sheet in CPIC warfarin guidelines }\end{array}$ \\
\hline
\end{tabular}

CPIC: Clinical pharmacogenomics implementation consortium,CYP2C9: Cytochrome 450 2C9, DVT: Deep vein thrombosis, INR: International normalized ratio, MAE: Mean absolute error, PE: Pulmonary embolism, $\mathrm{R}^{2}$ : Coefficient of determination, VKORC1: Vitamin k epoxide reductase complex 1, VTE: Venous thromboembolism

a higher explanation for warfarin maintenance dose $\left(\mathrm{R}^{2}\right.$ of $26 \%$ vs. $0 \%$ ) and a lower mean absolute error (MAE $9.9 \mathrm{mg}$ vs. $13 \mathrm{mg}$ ) when compared to fixed dosing. However, there has been no head to head comparison between fixed and clinical dosing strategies to the best of our knowledge. Genetic dosing that encompasses genetic factors in addition to clinical factors has been studied extensively over the last decade. Many observational studies were able to show that clinical and genetic factors together could explain more than $50 \%$ of warfarin maintenance dose variability. However, looking at the bigger picture, three clinical utility studies compared genetic-guided dosing to standard dosing but the results were controversial. Thus, genetic-guided warfarin dosing is still not adopted by guidelines. Because of that reason, the lack of accessibility to genetic testing and the increased use of DOACs, genetic dosing of warfarin is not widely implemented. 


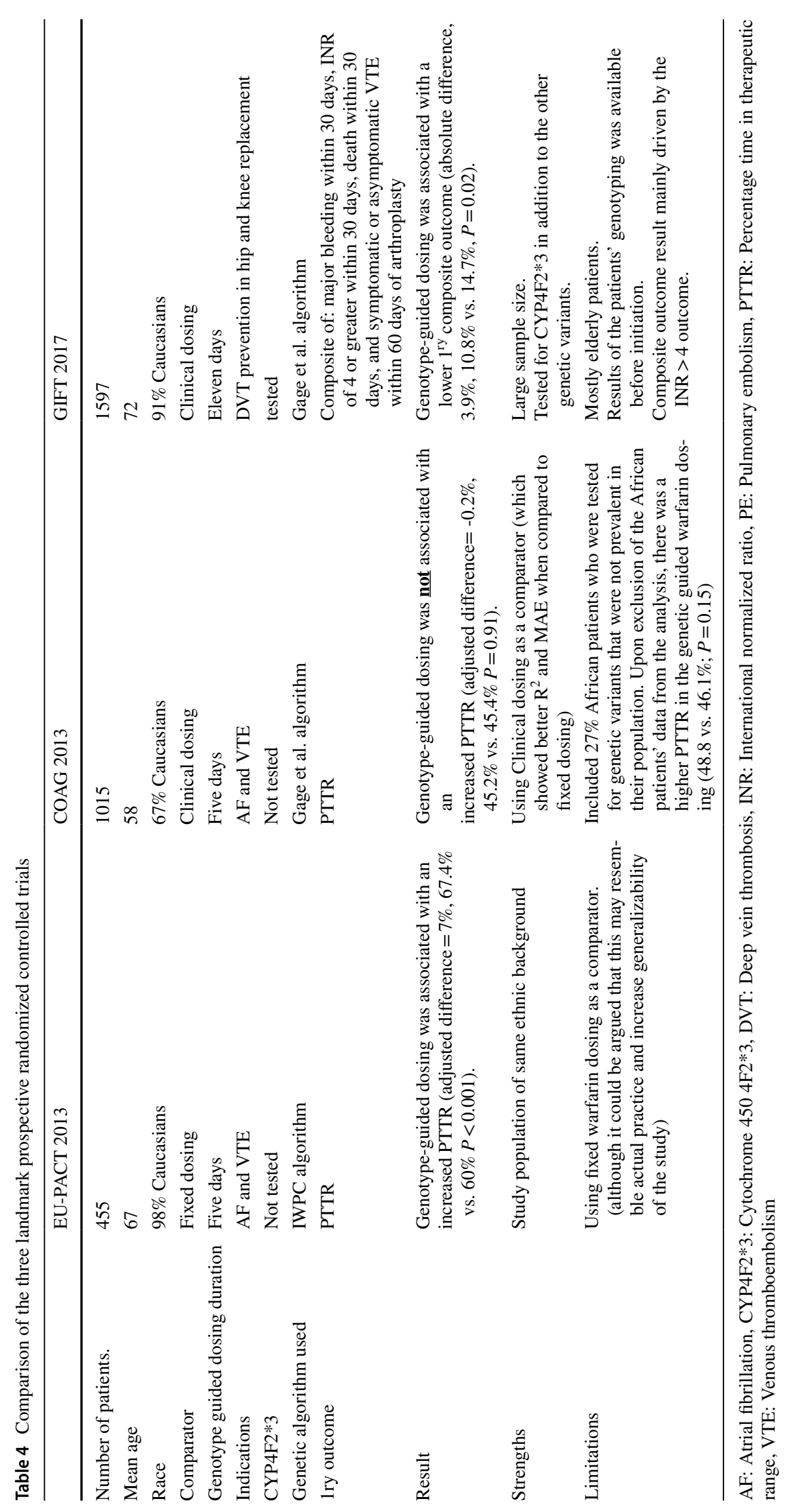




\section{Limitations}

While we attempted to include the most relevant studies, the reader is reminded that this is not a systematic review. With regards to fixed dosing method, guidelines were rather outdated (ACCP 2012) and therefore did not reflect the recent evidence in this regards. Also the most robust evidence with regards to genetic-guided warfarin dosing come from the Caucasian population.

\section{Conclusions}

A number of methods exist for warfarin initiation. Studies comparing different dosing methods for initiation yielded conflicting outcomes due to differences in study design, population studied, comparator, and outcomes measured. Looking at the big picture, the use of genetic dosing for warfarin initiation can lead to better outcomes. Whether these better outcomes are clinically or economically beneficial remains controversial. We acknowledge the diminishing role of warfarin in light of the DOACs widespread, but warfarin still remains the first therapeutic option for certain indications and an important therapeutic alternative for others as highlighted in the introduction. Also, the role of pharmacogenetic-guided warfarin dosing could be more obvious in developing countries where patients or insurance systems cannot afford DOACs. Further studies are needed to address these points in light of the decreasing costs and availability of genetic testing.

Acknowledgements The authors wish to thank Dr. Christina Aquilante (University of Colorado Skaggs School of Pharmacy) for her efforts in revising this manuscript.

Funding Open Access funding provided by the Qatar National Library. Grant: IRGC-06-JI-19-205 (Qatar).

Conflicts of interest The authors have no conflicts of interest to report.

Open Access This article is licensed under a Creative Commons Attribution 4.0 International License, which permits use, sharing, adaptation, distribution and reproduction in any medium or format, as long as you give appropriate credit to the original author(s) and the source, provide a link to the Creative Commons licence, and indicate if changes were made. The images or other third party material in this article are included in the article's Creative Commons licence, unless indicated otherwise in a credit line to the material. If material is not included in the article's Creative Commons licence and your intended use is not permitted by statutory regulation or exceeds the permitted use, you will need to obtain permission directly from the copyright holder. To view a copy of this licence, visit http://creativecommons.org/licenses/by/4.0/.

\section{References}

1 Perreault S, de Denus S, White-Guay B, et al. Oral anticoagulant prescription trends, profile use, and determinants of adherence in patients with atrial fibrillation. Pharmacotherapy. 2020;40:40-54.

2 Pengo V, Denas G, Zoppellaro G, et al. Rivaroxaban vs warfarin in high-risk patients with antiphospholipid syndrome. Blood. 2018;132:1365-71.

3 Garrett AD. Dabigatran vs. Warfarin in patients with mechanical heart valves. Drug Top. 2013;396:1206-20.

4 Ageno W, Gallus AS, Wittkowsky A, et al. Oral anticoagulant therapy-Antithrombotic therapy and prevention of thrombosis, 9th ed: American College of Chest Physicians evidence-based clinical practice guidelines. Chest. 2012;141:e44-88.

$5 \mathrm{Li}$ X, Li D, Wu JC, et al. Precision dosing of warfarin: open questions and strategies. Pharmacogenomics J. 2019;19:219-29.

6 Johnson JA, Caudle KE, Gong L, et al. Clinical pharmacogenetics implementation consortium (CPIC) guideline for pharmacogenetics-guided warfarin dosing: 2017 update. Clin Pharmacol Ther. 2017;102:397-404.

7 Heneghan C, Tyndel S, Bankhead C, et al. Optimal loading dose for the initiation of warfarin: a systematic review. BMC Cardiovasc Disord. 2010;10(1):1-2.

8 Ageno W, Gallus AS, Wittkowsky A, et al. Oral anticoagulant therapy. Chest. 2012;141:e44S-e88S.

9 Crowther MA, Ginsberg JB, Kearon C, et al. A randomized trial comparing 5-mg and 10-mg warfarin loading doses. Arch Intern Med. 1999;159:46-8.

10 Kovacs MJ, Rodger M, Anderson DR, et al. Comparison of $10-\mathrm{mg}$ and 5-mg warfarin initiation nomograms together with low-molecular-weight heparin for outpatient treatment of acute venous thromboembolism: a randomized, double-blind. Controlled Trial Ann Intern Med. 2003;138:714-9.

11 Quiroz R, Gerhard-Herman M, Kosowsky JM, et al. Comparison of a single end point to determine optimal initial warfarin dosing ( $5 \mathrm{mg}$ versus $10 \mathrm{mg}$ ) for venous thromboembolism. Am J Cardiol. 2006;98:535-7.

12 Monkman K, Lazo-Langner A, Kovacs MJ. A 10 mg warfarin initiation nomogram is safe and effective in outpatients starting oral anticoagulant therapy for venous thromboembolism. Thromb Res. 2009;124:275-80.

13 Mahtani KR, Heneghan CJ, Nunan D, et al. Optimal loading dose of warfarin for the initiation of oral anticoagulation. Cochrane Database Syst Rev. 2012;12.

14 Garcia P, Ruiz W, Loza Munárriz C. Warfarin initiation nomograms for venous thromboembolism. Cochrane Database Syst. Rev. 2016.

15 Ansell J, Hirsh J, Hylek E, et al. Pharmacology and management of the vitamin K antagonists: American College of Chest Physicians Evidence-Based Clinical Practice Guidelines (8th Edition). Chest. 2008 Jun;133(6 Suppl):160S-198S.

16 Keeling DM, Baglin T, Tait C, et al. Guidelines on oral anticoagulation with warfarin-fourth edition. Br J Haematol. 2011;154:311-24.

17 Gage B, Eby C, Johnson J, et al. Use of pharmacogenetic and clinical factors to predict the therapeutic dose of warfarin. Clin Pharmacol Ther. 2008;84:326-31.

18 Gage BF, Eby C, Milligan PE, et al. Use of pharmacogenetics and clinical factors to predict the maintenance dose of warfarin. Thromb Haemost. 2004;91:87-94.

19 Consortium TIWP. Estimation of the warfarin dose with clinical and pharmacogenetic data. N Engl J Med. 2009;360:753-64.

20 Dobrzanski S, Duncan SE, Harkiss A, et al. Age and weight as determinants of warfarin requirements. J. Clin. Pharm. Ther. 1983. p. 75-7. 
21 Redwood M, Taylor C, Bain BJ, et al. The association of age with dosage requirement for warfarin. Age Ageing. 1991;20:217-20.

22 Gurwitz JH, Avorn J, Ross-Degnan D, et al. Aging and the anticoagulant response to warfarin therapy. Ann Intern Med. 1992;116:901-4.

23 Shendre A, Parmar GM, Dillon C, et al. Influence of age on warfarin dose, anticoagulation control, and risk of hemorrhage. Pharmacotherapy. 2018;38:588-96.

24 Mueller JA, Patel T, Halawa A, et al. Warfarin dosing and body mass index. Ann Pharmacother. 2014;48:584-8.

25 Tellor KB, Nguyen SN, Bultas AC, et al. Evaluation of the impact of body mass index on warfarin requirements in hospitalized patients. Ther Adv Cardiovasc Dis. 2018;12:207-16.

26 Absher RK, Moore ME, Parker MH, et al. Patient-specific factors predictive of warfarin dosage requirements. Ann Pharmacother. 2002;36:1512-7.

27 Dang MTN, Hambleton J, Kayser SR. The influence of ethnicity on warfarin dosage requirement. Ann Pharmacother. 2005;39:1008-12.

28 Salem M, Eljilany I, El-Bardissy A, et al. Genetic polymorphism effect on warfarin-rifampin Interaction: a case report and review of literature. Pharmgenomics Pers Med. 2021;14:149.

29 Lexicomp ${ }^{\circledR}$ Drug Interactions. UpToDate. [cited 2021 Jul 3]. Available from: https://0-www.uptodate.com.mylibrary.qu.edu. qa/drug-interactions/\#di-druglist.

30 Cavallari LH, Shin J, Perera MA. Role of pharmacogenomics in the management of traditional and novel oral anticoagulants. Pharmacotherapy. 2011;31:1192-207.

31 Whirl-Carrillo M, McDonagh EM, Hebert JM, et al. Pharmacogenomics knowledge for personalized medicine. Clin Pharmacol Ther. 2012;92:414-7.

32 Home-KNMP.nl. [cited 2021 May 30]. Available from: https:// www.knmp.n1/.

33 Relling MV, Klein TE. CPIC: clinical pharmacogenetics implementation consortium of the pharmacogenomics research network. Clin Pharmacol Ther. 2011;89:464-7.
34 Johnson JA, Caudle KE, Gong L, et al. CPIC guideline for pharmacogenetics-guided warfarin dosing-Supplement v2.0. Clin Pharmacol Ther. 2017;1-40.

35 FDA. Coumadin (warfarin sodium) tablets Label.

36 Avery PJ, Jorgensen A, Hamberg AK, et al. A proposal for an individualized pharmacogenetics-based warfarin initiation dose regimen for patients commencing anticoagulation therapy. Clin Pharmacol Ther. 2011;90:701-6.

37 Lenzini P, Wadelius M, Kimmel S, et al. Integration of genetic, clinical, and INR data to refine warfarin dosing. Clin Pharmacol Ther. 2010;87:572-8.

38 Kimmel SE, French B, Kasner SE, et al. A pharmacogenetic versus a clinical algorithm for warfarin dosing. N Engl J Med. 2013;369:2283-93.

39 Pirmohamed M, Burnside G, Eriksson N, et al. A randomized trial of genotype-guided dosing of warfarin. N Engl J Med. 2013;369:2294-303.

40 Gage BF, Bass AR, Lin H, et al. Effect of genotype-guided warfarin dosing on clinical events and anticoagulation control among patients undergoing hip or knee arthroplasty: the GIFT randomized clinical trial. J Am Med Assoc. 2017;318:1115-24.

41 PharmGKB [cited 2022 Jan 8]. Available from: https://www. pharmgkb.org/

42 King CR, Deych E, Milligan P, et al. Gamma-glutamyl carboxylase and its influence on warfarin dose. Thromb Haemost. 2010;104:750-4.

43 Voora D, Koboldt D, King C, et al. A polymorphism in the VKORC1-regulator calumenin predicts higher warfarin doses in African-Americans. Clin Pharmacol Ther. 2010;87:445-51.

Publisher's Note Springer Nature remains neutral with regard to jurisdictional claims in published maps and institutional affiliations. 